\title{
Una sinagoga desvelada en Sevilla: estudio arquitectónico
}

Óscar Gil Delgado

Universidad de Sevilla

\begin{abstract}
La iglesia de Santa María la Blanca de Sevilla se levanta en el mismo solar donde, entre 1248 y 1391, estuvo la sinagoga mayor de la judería, situada, a su vez, sobre una mezquita anterior, próxima a una de las puertas de la ciudad. Hasta hoy no se habían identificado con claridad vestigios ni de la sinagoga ni de la mezquita que, salvo unos escasos restos formados por unos pocos fustes y dos capiteles reaprovechados, se creían desaparecidos. Los trabajos que he llevado a cabo desde 1999 en la iglesia y, sobre todo, a raíz de las obras y el proyecto de restauración que he dirigido, han puesto de manifiesto estructuras y restos de las etapas anteriores del edificio. El presente artículo tiene por objeto la descripción razonada y documentada gráficamente de estos episodios.
\end{abstract}

Palabras Clave: Sevilla; Santa María la Blanca; mezquita; sinagoga; iglesia; judería; aljama; medieval; mudéjar; barroco.

A Synagogue Unveiled in Seville: Architectural Study.- Close to the entrance of the city of Sevilla where the Santa Maria la Blanca church stands is the location of the Grand synagogue of the Jewish quarter (1248 and 1391) and previous to the synagogue, a mosque. Up to today no vestiges neither of the synagogue nor of the mosque have been confirmed, except for a few scanty remains formed by a few columns and two capitals. The author's work of the last years immediately after the church's restoration, have revealed structures and remains of the previous stages of the building. The present article describes and documents graphically the vestiges of the two earlier structures.

Keywords: Seville; Santa Maria la Blanca; Mosque; Synagogue; Church; Jewish Quarter; Jewish Community; Medieval; Mudejar; Baroque.

Tras la incorporación de Sevilla a la Corona de Castilla en 1248, se delimitó una zona en el sureste de la ciudad, destinada a servir de judería. Las mezquitas anteriores que se encontraban en su interior fueron

\footnotetext{
*oscar@us.es
} 
destinadas a sinagogas ' . Después del asalto sufrido por la judería en 1391, dos de estas sinagogas se convertirían en iglesias, con los nombres de Santa Cruz y Santa María de las Nieves ${ }^{2}$, y en algún momento posterior a 1482 se incorporaría la última sinagoga al uso religioso cristiano, con el nombre de San Bartolomé (figura 1).

La trayectoria de estas tres sinagogas durante la etapa en la que el sector fue aljama es poco conocida por falta de datos documentales ${ }^{3}$. Aunque hay documentos referentes a sinagogas en la judería de Sevilla, no hay certeza de que correspondan a alguna de las tres sinagogas citadas ${ }^{4}$. A partir de su conversión en iglesia, las tres antiguas sinagogas corren suertes distintas. Así, la actual iglesia de San Bartolomé ocupa el lugar donde estuvo una sinagoga que se reutilizó como iglesia con dicho nombre ${ }^{5}$ hasta que fue demolida y reedificada en el siglo XVIII, por ruina del templo antiguo $^{6}$. La que se conocía en aquel tiempo como iglesia de Santa Cruz

\footnotetext{
${ }^{1}$ Antonio Ballesteros, Sevilla en el siglo XIII (Madrid, 1913), doc. 8, págs. VIII-XI (privilegio rodado de Alfonso X, de 5 de agosto de 1252, confirmando otro anterior de Fernando III por el que se donan a la Iglesia de la ciudad todas las mezquitas de la etapa islámica, salvo las tres que están en la judería y que son, en ese momento, sinagogas de los judíos). Una reproducción del documento se encuentra en AA. VV, Catedral. Magna Hispalensis. El universo de una Iglesia: Catálogo de la exposición (Sevilla: Comisaría de la Ciudad de Sevilla para 1992, 1992), pág. 137-138 (Archivo Catedral, FHG, leg. 4, 36/1). Sobre la judería antes de 1248 y hasta 1391 puede consultarse Isabel MonTES Romero-CAMACHO, «Notas para el estudio de la judería sevillana en la Baja Edad Media (1248-1391)», Historia, Instituciones, Documentos 10 (1983), 251-277.

${ }^{2}$ También fue conocida esta iglesia durante los primeros tiempos como Santa María la Nueva, al igual que el barrio sería llamado el Barrio Nuevo.

${ }^{3}$ Hay noticias posteriores al asalto de 1391 donde se reconocen bienes que poseían las antiguas sinagogas de Santa Cruz y Santa María la Blanca en Mario Méndez Bejarano, Historia de la judería de Sevilla (Madrid: Editorial Ibero-Africano-Americana, 1922), 175-176 («Dote de la Igresia de Senta María la Nueva [Que antes era sinagoga fecho por el regimiento de Sevilla]).

${ }^{4}$ Yolanda Moreno Koch, «Nueva documentación sobre las sinagogas de Sevilla», en Actas del VII Congreso Internacional Encuentro de las Tres Culturas (Granada: Universidad, 1991), 269-275. Heather L. ECKER, «The Conversion of Mosques to Synagogues in Seville: The Case of the Mezquita de la Judería», Gesta 36 [= Visual Culture of Medieval Iberia] (1997), 190-207.

${ }^{5}$ Rodrigo Caro. Antigüedades y Principado de la ilustrissima ciudad de Sevilla y Chorographia de su convento iuridico, o antigua Chancilleria (Sevilla, 1634).

${ }^{6}$ Había inscripciones hebreas en esta iglesia.
} 


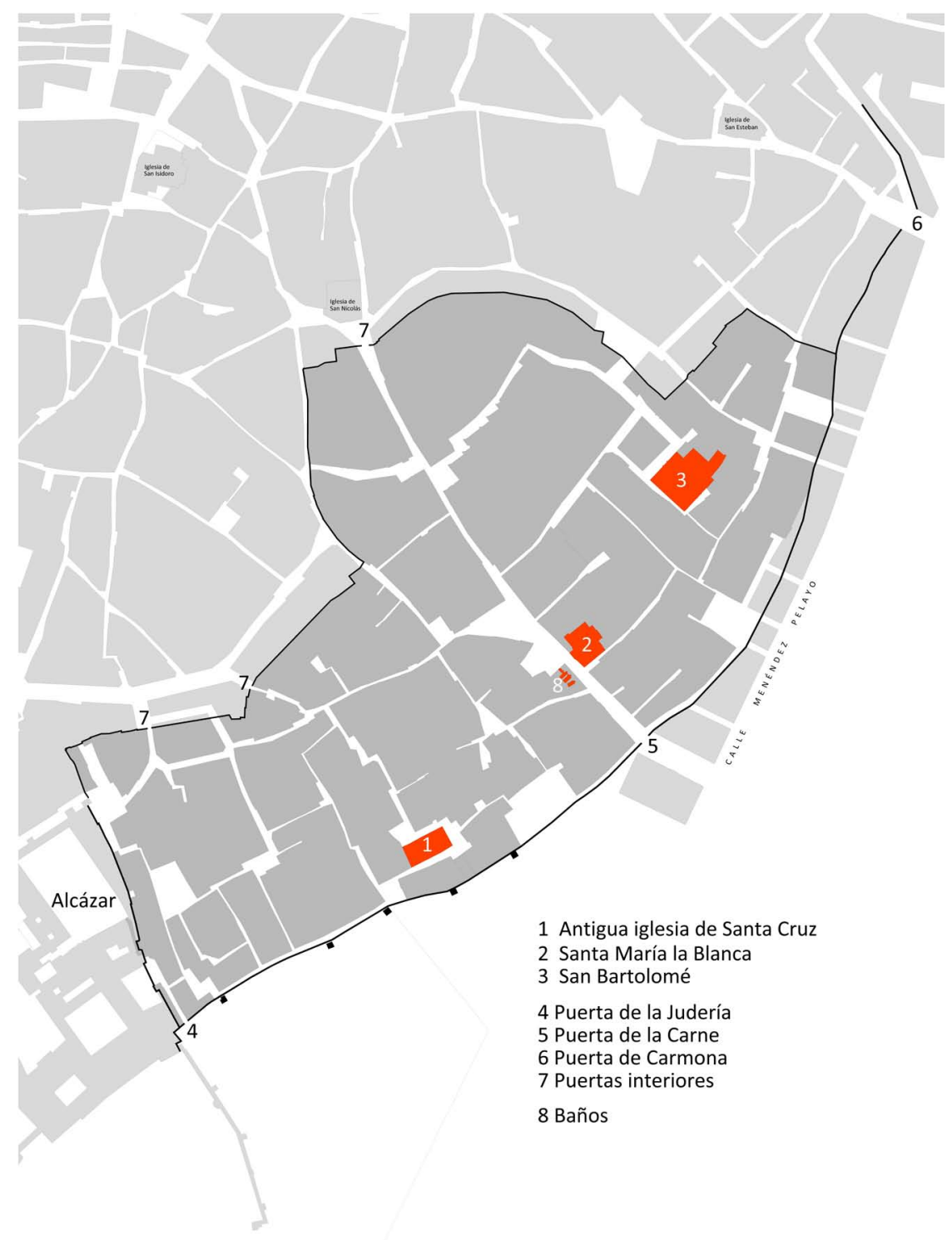

Figura 1. Plano del sector de la antigua judería de Sevilla con la situación de las tres sinagogas. 
se situaba en la plaza que hoy tiene ese nombre y fue demolida en 1811 durante la ocupación francesa. La parroquia se trasladó sucesivamente a dos conventos para terminar en el primero, antiguo de Clérigos Menores, situado en la actual calle Mateos Gago (antigua Borceguinería). Por último la iglesia parroquial de Santa María la Blanca sufrió una profunda transformación en el siglo XVII ${ }^{7}$, con motivo del júbilo por la publicación en 1661 de un breve pontificio del papa Alejandro VII en apoyo al culto de la Inmaculada Concepción. Con motivo de las fiestas que se hicieron para celebrar la reapertura de la iglesia en 1665, el clérigo Fernando de la Torre Farfán escribió una relación donde, entre otras consideraciones, se describía la obra que se había realizado en la iglesia ${ }^{8}$. Inmerso en el ambiente sevillano de este siglo y, quizá, en un elogio exagerado de la obra, el autor describe que la iglesia fue reconstruida completamente y que solo había quedado en pie la capilla mayor que, a su vez, había sido reconstruida cinco años antes ${ }^{9}$.

${ }^{7}$ La transformación de iglesias durante los siglos XVII y XVIII, mediante la adición de bóvedas de yesería fue muy corriente en España. Era una forma económica de renovación al gusto barroco. De esta forma se han mantenido numerosos programas decorativos medievales ocultos tras estas bóvedas. Una descripción ejemplar de estas reformas se explica en Leopoldo ToRres BALBÁs, «La iglesia mudéjar de Santa Clara en Guadalajara», en Crónica arqueológica de la España musulmana XXXI (Crónica de la España musulmana 2), 333-338 (Madrid: Instituto de España, 1981): «Las iglesias que se prestaban admirablemente para esa transformación eran las mudéjares de ladrillo, casi siempre pobres y desnudas. En Castilla, Aragón y Andalucía disfrazáronse infinidad de ellas. A sus sencillos pilares se adosaron pilastras; los arcos agudos pasaron a ser, mediante añadidos de yeso, de medio punto; corriéronse molduras sobre los arcos y las pilastras y, por encima de los entablamentos así dispuestos, volteáronse bóvedas de medio cañón con lunetos de ladrillo, tabicadas unas veces, otras con camones de madera, cañizo y yeso, ocultando las armaduras de par y nudillo, cubierta de casi todas» (ibíd., 334).

${ }^{8}$ Fernando de la Torre Farfán, Fiestas que celebró la Iglesia Parrochial de S. María la Blanca, capilla de la Sta. Iglesia Metropolitana y Patriarchal de Seuilla, en obsequio del nueuo breue concedido por N. Smo. Padre Alejandro vij, en fauor del Puríssimo Mysterio de la Concepción sin Culpa Original de María...: con la circunstancia de auerse fabricado de nuebo su Templo para esta fiesta (Sevilla: Juan Gómez de Blas, 1666).

${ }^{9}$ «Postróse, pues, lo material del edificio antiguo, a la valiente resolución. Quedó solo en pie lo que pertenece a la Capilla mayor; corta parte, y essa respetada por la excelencia de su obra; y tan moderna, que fue su fabrica empeño ancedente del mismo cuydado, que ahora sudava en este exercicio; tanto, que parece que el intento avía començado entonces para proseguir ahora. Tenia de anterioridad solos cinco años; tiempo que suele darse, con providencia para el buen asiento de los materiales» (ibíd., fols. 1-2). 


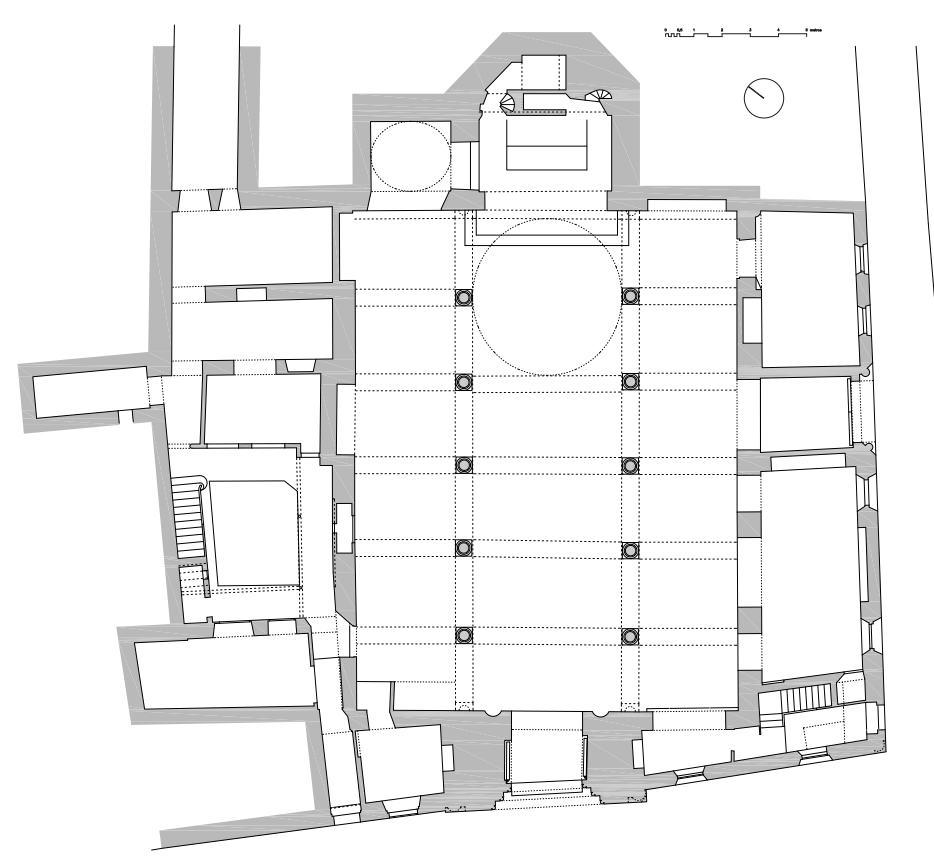

Plano 1. Planta de la iglesia y casa parroquial.

La descripción contenida en esta relación, unido a que se transformó por completo el aspecto del interior de la iglesia ${ }^{10}$, ha provocado que en casi toda la etapa posterior se creyera que los restos de la sinagoga desaparecieron, derruidos, en este momento. No obstante, algunos analistas de la iglesia apuntaron en su momento posibles preexistencias o posibles estructuras primitivas subyacentes ${ }^{11}$.

${ }^{10}$ Curiosamente no se modificó la portada principal de la iglesia manteniendo la configuración gótico-mudéjar de su portada y primer cuerpo del campanario situado sobre ella.

${ }^{11}$ Otto Czeneluus, «Antiguas sinagogas de España», Arquitectura. Revista oficial de la Sociedad Central de Arquitectos, año XIII, núm. 150 (octubre 1931), 327-341: 332. Porque no tengo duda, que aún debe existir en España alguna, y que debajo de la decoración posterior, como en Santa María la Blanca de Sevilla, se esconda el cuerpo antiguo de la sinagoga. Véase también Diego Angulo IÑíguez, «Las pinturas de Murillo, de Santa María la Blanca», Archivo Español de Arte 42/165 (enero-marzo 1969), 13; Meir BEN-Dov, The Golden Age: Synagogues of Spain in History and Architecture (Jerusalem: Urim, 1989), 127-136. 
En 1999 se me hizo un encargo como arquitecto para dirigir las obras de reparación de unas filtraciones puntuales en la cubierta de la iglesia. Propuse a la administración tutelar responsable la realización de un levantamiento de los planos de la iglesia, ya que los pocos documentos existentes eran escasos e incompletos, trabajo llevado a cabo en el verano de 1999. En otoño del año 2000, durante una inspección de la estructura de la cubierta, situada por encima de las bóvedas de las yeserías barrocas, descubrí en la línea de coronación de los muros de la nave central de la iglesia una serie de arquillos ciegos, parcialmente ocultos por la presencia de lunetos, pertenecientes a una bóveda encamonada de cañón, construida en época barroca. Dada la fragilidad que le suponía a dichas bóvedas no me pareció soporte seguro para realizar una toma de datos detallada de este remate. Sin embargo, sí verifiqué que tenían que corresponder a un momento anterior del edificio ya que se trataba de una serie de arcos de herradura, levemente apuntados y que estaban modulados con los tramos de la nave a razón de dos arquillos por cada tramo. De la presencia de estos arcos se deducía que los muros de la nave, por consiguiente, no databan tampoco de época barroca, como se había descrito, y que lo que se había realizado era aprovechar la obra de fábrica y sustituir las columnas antiguas por otras nuevas, probablemente rectificando también el trazado de los arcos inferiores de la nave. Si los muros de la nave central, apoyados anteriormente también sobre columnas, habían sido aprovechados, no cabía pensar que no lo hubieran sido los muros perimetrales del cuerpo de la iglesia. El descubrimiento de estos arcos pasó bastante desapercibido por su situación oscura y poco accesible, y no se le dio más importancia al hecho hasta las obras de sustitución de las cubiertas en 2011.

La objeción documental a la relación de De la Torre Farfán sobre la reedificación completa de la iglesia, la supuso la publicación, en 2005, del libro Del Clasicismo al Barroco: Arquitectura sevillana del siglo XVII, en cuyos apéndices documentales está contenida una transcripción del contrato de las obras en la iglesia ${ }^{12}$. A su vez se incluye otro contrato

${ }^{12}$ Juan Antonio Arenillas, Del Clasicismo al Barroco: Arquitectura sevillana del siglo XVII (Sevilla: Diputación, 2005), 361-363 (1662, julio 8: Obligación de obra entre Juan González y el canónigo don Justino de Neve, iglesia de Santa María la Blanca, AHPS, Protocolos Notariales, leg. 12.964, fols. 661-662). Reproduzco texto más adelante. 
firmado un año después para la realización de las nuevas columnas en mármol rojo, procedente de Antequera ${ }^{13}$.

De la lectura analítica del contrato de obras se deduce claramente que la nave de la iglesia no fue demolida sino que se recreció para poder cobijar la bóveda prevista:

Primeramente para questa fabrica tenga arte supuesto que sea de descubrir siete varas de la armadura del tejado de la nabe principal junto al presbiterio aqui sea de hacer la caja para que la media naranja quepa obserbando los precetos y tambien lo restante de la armadura sea de descargar de teja para reformarla de madera y tejala con canales puedese entonces lebantar dicha armadura sin debaratarla tres quartas o una bara y luego recibirla criando las paredes con ladrillo y del gruesso que tienen y echarle por de fuera tres yladas de cornixa fortificarla de tabla y tirantes jarpacones o nudillos si fuere nesesario y echarle en los dos lados unos listones en las juntas de las tablas de las que se quitaren viejas porque ansi se fortifica a la armadura y el tejado quede seguro de correrse demas de lo dicho con esta diligencia cabe bien el cañon de lunetas porque su buelta sera semicirculo perfecto como en el borrador lo muestra la linea de puntos.

Los trabajos contratados consisten, en resumen, en desmontar la zona de cubierta donde se proyecta la cúpula para construir esta y cerrarla con una cubierta de pabellón a cuatro aguas. Desmontar el tejado y la estructura del resto de la nave y elevarla, labrando varias hiladas de ladrillo para poder inscribir la bóveda de cañón en la nave central. Para esta cubierta se reutilizaban los mismos cuchillos de madera existente y se volvía a tejarla unos ochenta centímetros (tres cuartos o una bara) más alta. La exactitud de esta previsión estaba apoyada por un dibujo al que se alude en el documento. Estas prescripciones implican claramente que no se demolieron los muros de las naves de la iglesia y que, por ese motivo, se encuentran hoy los arcos ciegos mudéjares en la coronación de dichos muros. Sobre las nuevas columnas de «jaspe colorado» no se voltearon nuevos arcos, simplemente se apearon los

${ }^{13}$ Arenillas, Del Clasicismo al Barroco, 364-365 (1663, julio, 23: Obligación de obra entre Gabriel de Mena y el canónigo don Justino de Neve, iglesia de Santa María la Blanca, AHPS, Protocolos Notariales, leg. 12.967, fols. 685r-v). 
arcos de la nave central, se retiraron las columnas antiguas, que no tenían relación estilística con la obra nueva, y se colocaron las nuevas. Con toda seguridad los arcos de la nave son los mismos antiguos de la sinagoga «mudéjar», recortados, redondeados y revestidos con molduras de yeso, según el nuevo gusto. El resto de los trabajos, consistente en el trazado de las bóvedas encamonadas, la ejecución de la tribuna a los pies y el solado con solería de barro de la iglesia no incidían en la obra antigua.

La obra de decoración barroca no dejó ninguna parte sin cubrir: las bóvedas con una profusión exuberante de yeserías sobre campo dorado en la nave central y más simples en las naves laterales; las superficies murales se decoran completamente con pinturas y en la base un zócalo de azulejos hasta dos metros de altura, en la totalidad del perímetro interior de la iglesia. Todo el programa decorativo se remataba con cuatro cuadros que Murillo pintó expresamente para la iglesia, dos medios tondos situados bajo la cúpula central sobre los muros de la nave, en el encuentro del teórico crucero, y otros dos en los tímpanos de remate, en la cabecera de las bóvedas de las naves colaterales.

La historia de estos cuadros, junto con otros muchos de Sevilla, es de sobra conocida ${ }^{14} \mathrm{y}$, de las cuatro obras requisadas por el ejército francés, volvieron dos modificadas en su forma, y se encuentran expuestas en el Museo Nacional del Prado. Desde principios del siglo XIX hasta finales del XX la iglesia lució el vacío de estos cuadros y, hacia 1970, el arquitecto Rafael Manzano Martos propuso y dirigió la realización de unas copias de los dos depositados en el Prado con objeto de recuperar en lo posible la apariencia original de la nave central.

Para la ejecución de las obras de reparación de las cubiertas de la iglesia en 2010 se desmontaron las copias situadas en la nave central $\mathrm{y}$, desde entonces, se encuentran depositadas en otra iglesia sevillana. Con motivo de las obras decidí aprovechar los medios auxiliares de la misma para documentar más detalladamente la obra mudéjar. Observé que, aunque la decoración barroca impedía inspeccionar los muros de la iglesia, precisamente la pared descubierta tras los grandes lienzos de

\footnotetext{
${ }^{14}$ Ignacio Cano Rivero, «Coleccionismo y dispersión de la obra de Murillo en los siglos XVIII y XIX», en Murillo y Justino de Neve: el arte de la amistad. Catálogo de la exposición (Madrid, 2012), 88-89.
} 


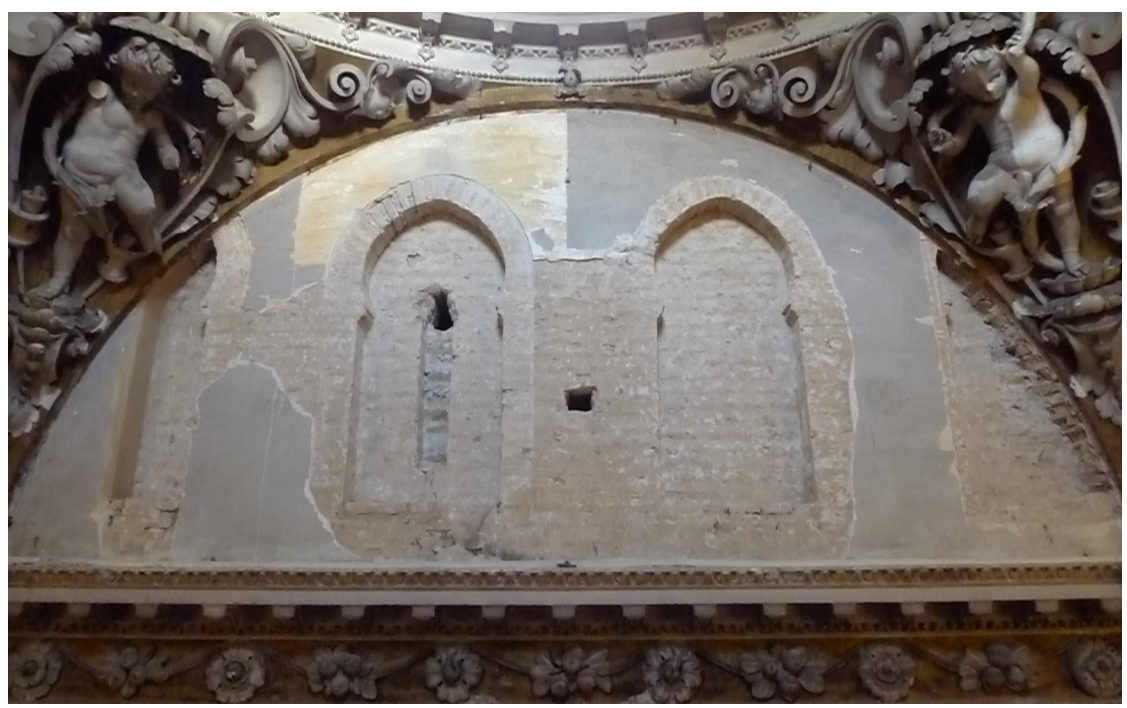

Fotografía 1. Tímpano del falso crucero con las ventanas descubiertas.

la nave central ofrecía una superficie libre de motivos decorativos y por donde se podía «asomar» la obra antigua hacia el interior de la iglesia. Con este motivo, se procedió a picar el enlucido sobre estos planos ${ }^{15}$ apareciendo la primera serie de arquillos de remate de este muro de la nave central, que por su composición y estilo pertenecen con toda seguridad a una obra mudéjar para sinagoga ${ }^{16}$ (fotografía 1 ).

La aparición de esta obra, ejecutada durante la etapa judía, conlleva a la constatación del edificio como una mezquita documentada ${ }^{17}$; esta fue reutilizada como sinagoga a partir de 1248 , reedificada y ampliada con

${ }^{15}$ Previo al picado de los arcos se realizaron, por el equipo de restauración de la obra, catas para prevenir daños a posibles yeserías o pinturas subyacentes medievales, sin que aparecieran restos.

${ }^{16}$ La posibilidad de que fueran una obra mudéjar cristiana, posterior a 1391, es muy poco factible al no existir ninguna obra similar en la arquitectura religiosa cristiana de esa época. Aunque varias iglesias mudéjares sevillanas presentan ventanas en la coronación del muro de la nave central siempre son ventanas aisladas (normalmente una por tramo de nave) y nunca una serie de arquillos ciegos hacia el interior.

${ }^{17}$ Según el citado privilegio de donación. 

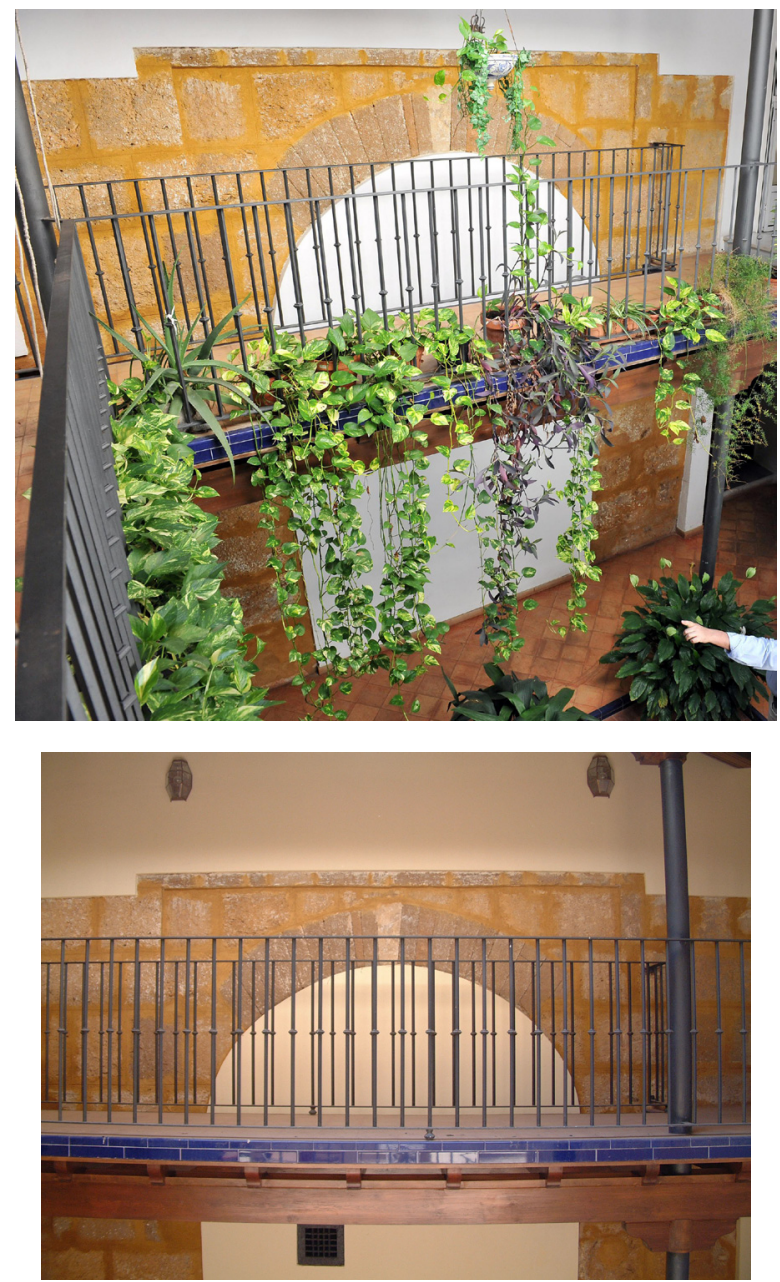

Fotografía 2. Puerta de acceso desde el patio.

una obra mudéjar para proseguir su uso como sinagoga ${ }^{18} \mathrm{y}$ transformada a partir de 1391 en iglesia, que se reformaría profundamente en el siglo XVII para adquirir la imagen interior que, principalmente, hoy se percibe.

${ }^{18}$ Probablemente fue la sinagoga mayor de la aljama sevillana por la posición central que ocupaba en la judería. Jaume RIERA I SANS, Els poders públics i les sinagogues. Segles XIII-XV (Girona: Call de Girona, 2006), 188: «Les sinagogues de les grans capitals amb antics assentaments de jueus, solen trobar-se al centre de la zona habitada per ells, estigui elevat o no». 


\section{El EDIFICIO ISLÁMICO}

Para tratar de la etapa musulmana de este templo hay que señalar que, adosada al muro norte de la iglesia -muro del evangelio- había una casa destinada a vivienda parroquial. Esta casa se organizaba en torno a un patio, fronterizo en uno de sus lados con el citado muro. En dicho muro se observaba un rehundido en forma de marco o alfiz de una puerta, casi oculto tras múltiples capas de encalado. La antigua casa parroquial, completamente arruinada, existió hasta el año 2000, año en que se llevó a cabo su demolición completa y la reedificación de la misma desde los cimientos $^{19}$. En la demolición tuve acceso al espacio vacío de esta casa y pude fotografiar los restos de este hueco y de otro que descubrí en el mismo muro de la iglesia, situado más próximo a la cabecera y sobre el que volveré más tarde ${ }^{20}$.

La puerta que aparece en el muro es una portada que por el exterior presenta una fábrica de sillares de piedra tipo albero, de uso habitual en Sevilla. El arco de la puerta, enmarcado por el alfiz, se dispone presentando en la mitad superior de su desarrollo un dovelaje de sillares pequeños con sus juntas apuntando claramente a un punto situado por debajo del centro del arco (fotografía 2). Tanto el aparejo del arco como el material empleado indican que podría tratarse de un arco túmido de época islámica, de un periodo anterior a la última época almohade ${ }^{21}$ sevillana (siglos XII-XIII). Por otra parte, la situación del edificio, en una arteria importante y próxima a una puerta de la ciudad, apoya la hipótesis de la presencia de una mezquita en estas inmediaciones. La importancia del sitio lo resalta la presencia de unos baños en las inmediaciones de esta mezquita ${ }^{22}$. Según las teorías clásicas ${ }^{23}$, la mezquita estaría situada

${ }^{19}$ La planta que se representa en el plano es la de la casa antigua. La planta del estado actual me ha sido facilitada recientemente por el arquitecto de dicha obra.

${ }^{20}$ A partir de esta inspección ya no me fue posible el acceso al interior de esta obra hasta su finalización.

${ }^{21}$ El material utilizado, dovelas de piedra en vez de rosca de ladrillos y la situación intramuros del edificio apuntan a este origen.

${ }^{22}$ Los restos de este hammam se sitúan en frente de la iglesia, en la calle Santa María la Blanca, en el semisótano de unos establecimientos.

${ }^{23}$ Magdalena Valor Piechotta, José Ramírez del Río, «Sobre la cronología de las murallas», en Magdalena VAlor, Ahmed Tahirí (coords.), Sevilla Almohade. Catálogo 
extramuros de la cerca antigua heredada de los romanos, junto a una de sus puertas, en una zona donde el urbanismo desbordó los límites de la ciudad $^{24}$; quedando inclusa en el recinto almohade.

Observando el conjunto de la planta de la iglesia y la casa rectoral, una vez situada esta puerta anterior, podría deducirse una posible configuración de mezquita, con patio situado al norte de la sala de oración. A partir de las dimensiones actuales de la iglesia, supuse la posibilidad de que la sala de oración se cerrara hacia el noreste mediante otro muro, que discurriría paralelo al de los pies de la actual iglesia, simétricamente situado respecto del eje de dicha puerta y patio. Efectivamente, en las prospecciones realizadas antes de las obras, en el año 2000, apareció en esa zona, junto a una de las columnas de la iglesia, las trazas de un muro primitivo que se sitúa en la posición indicada en el plano; las posteriores excavaciones arqueológicas corroboraron esta existencia ${ }^{25}$. Si la planta de la mezquita tenía acceso desde el patio con eje en la puerta descubierta, la situación del mihrab se encontraría en prolongación de este eje, en el muro de la alquibla. Este último fue descubierto en las excavaciones arqueológicas de 2012, no en el muro de la epístola, como yo supuse en un principio, sino paralelo a él, a poca distancia hacia el interior de la nave, de manera que la planta de la mezquita presenta forma cuadrada, aproximadamente de 11,50 x 11,50 m. La sala de oración estaba dividida en tres naves perpendiculares al muro de la alquibla, posiblemente con tres o cuatro arcos, según las dimensiones de la sala ${ }^{26}$. El cierre septentrional del patio se diluye entre los inmuebles vecinos, pero bien pudo ser también cuadrado en un principio, o adaptado a los límites de las líneas medianeras de

exposición (Sevilla-Rabat: Universidad de Sevilla, Fundación Tres Culturas del Mediterráneo, Universidad Hassán II de Mohamedia, 1999), 27-39.

${ }^{24}$ Rafael Valencia RodríGueZ, «El palacio de Altamira y su entorno durante la Alta Edad Media», en Diego Oliva Alonso (coord.), La restauración del Palacio de Altamira (Sevilla: Consejería de Cultura, Junta de Andalucía, 2005), 18.

${ }^{25}$ La base del muro apareció, a su vez, en otra cata realizada hacia el centro de la nave de la iglesia.

${ }^{26}$ Durante las excavaciones arqueológicas han aparecido unos retallos de fábrica en el arranque del muro, a cada lado de la puerta que deben tener relación con la división en tres naves. 
los edificios colindantes en su caso. El acceso a la mezquita se debió realizar a través del sahn o, con menos probabilidad, contó además con entrada directa a la sala de oración desde la calle (plano 2).

El patio no sólo estaba conectado con la actual calle Santa María la Blanca, a poniente, sino que se conserva el resto de un pequeño callejón que aislaba en una manzana independiente la mezquita y sus dependencias anejas. Esta calleja, que continúa hoy incrustada en el parcelario, arrancaba de la actual calle Archeros y rodeaba la casa medianera con la mezquita por el este para volver hacia el oeste hasta

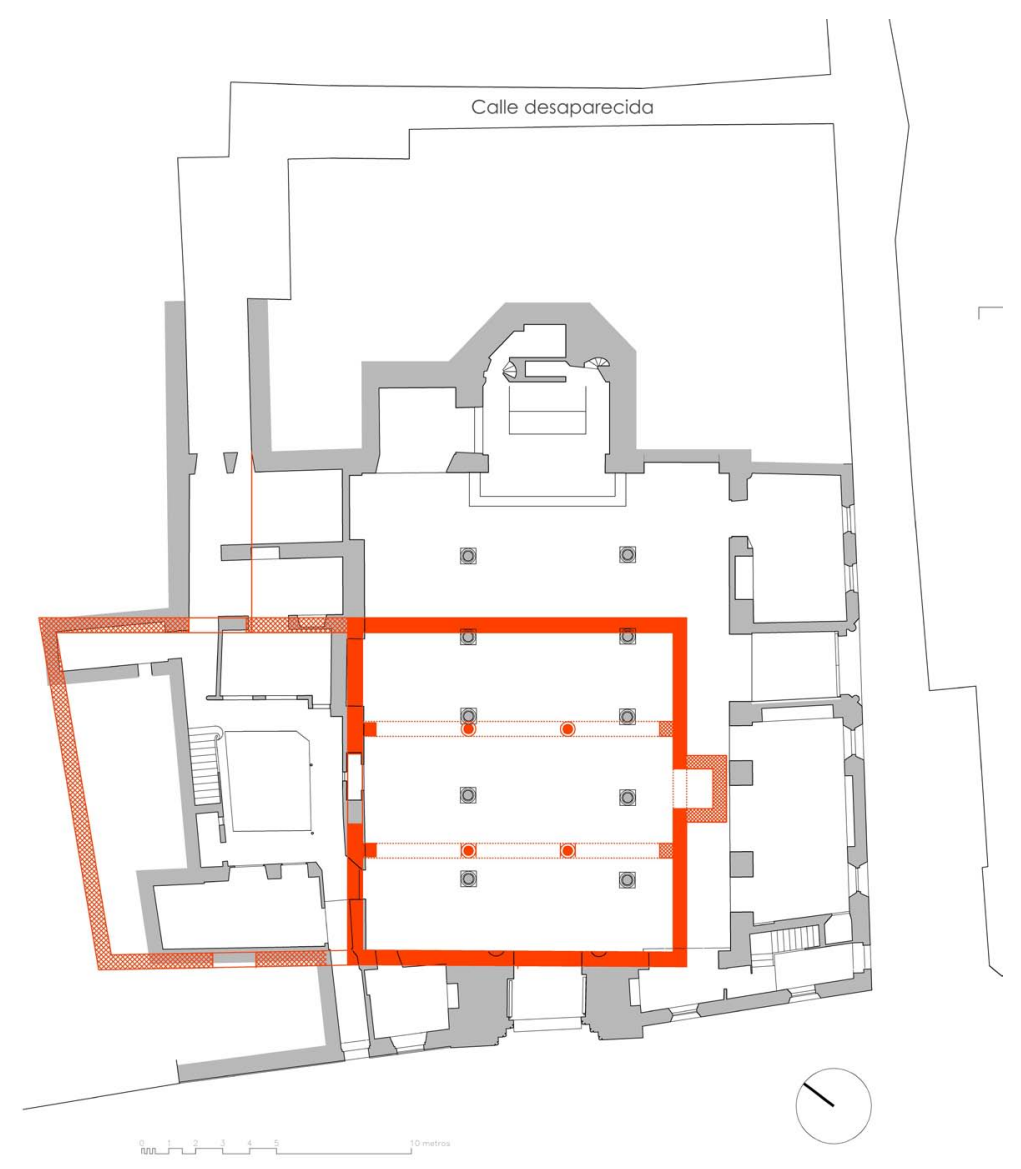

Plano 2. Planta de la mezquita superpuesta a la planta actual de la iglesia 
encontrarse con el patio. El callejón fue clausurado en el siglo XVIII y se debe relacionar con una interesante solicitud hecha por la iglesia al Ayuntamiento de la ciudad ${ }^{27}$.

\section{El EDIFICIO JUDío}

En algún momento de su utilización por los judíos como sinagoga, la antigua mezquita ${ }^{28}$ se transformó profundamente, ampliándose para constituir una sinagoga de planta basilical con la misma configuración que hoy tiene. La datación de esta reforma es bastante imprecisa; desde luego, la obra es mudéjar y tiene similitudes con otras contemporáneas en Toledo y Segovia. Ante la prohibición de construir nuevas sinagogas ${ }^{29}$, podría tratarse de una obra nueva enmascarada como reforma, en algún momento durante el último tercio del siglo XIII o el siglo XIV. La reedificación de la sinagoga podría situarse, a su vez, en la misma época en que en el resto de Sevilla se decidió reformar varias iglesias, debido al terremoto ocurrido en 1356, formando lo que Angulo denominó el grupo de iglesias de dicho año ${ }^{30}$. Poco antes, en 1354, se había producido el primer ataque

${ }^{27}$ Yolanda Fernández CACHo, «Memorial de don Manuel Monsalve, mayordomo de la fábrica de Santa María la Blanca para tapiar una callejuela junto a la iglesia por los perjuicios que ocasionaba», en Oliva Alonso (coord.), La restauración del palacio de Altamira (Apéndice documental), 436.

${ }^{28}$ No hay noticias sobre el proceso de transformación en sinagoga; la conversión de mezquitas en iglesias en Sevilla está más documentado en Magdalena Valor PiechotTa, Isabel Montes Romero-Camacho, «De mezquitas a iglesias: el caso de Sevilla», en Religion and Belief in Medieval Europe. Papers of the «Medieval Europe» Brugge Conference, eds. Guy de Boe, Frans Verhaeghe (Brugge, 1997), vol. IV, 139-148.

${ }^{29}$ Libro de las Siete Partidas del rey D. Alfonso el Sabio (Madrid: Real Academia de Historia, 1807), tomo III, Partida VII, título XXIV, ley IV: «Cómo pueden haber los judíos sinagogas entre los cristianos. Sinagoga es lugar do los judíos facen oración: et tal casa como esta non pueden facer nuevamente en ningún lugar de nuestro señorio a menos de nuestro mandado. Pero las que habien antiguamente si acaeciese que se derribasen, puédenlas reparar et facer en aquel mismo suelo, asi como enante estaban, non las alargando mas, nin las alzando, nin las faciendo pintar». El Concilio provincial de Zamora, celebrado en 1313, dictaba normas prohibiendo la construcción de nuevas sinagogas.

${ }^{30}$ Diego Angulo ÍñIguEZ, Arquitectura mudéjar sevillana de los siglos XIII, XIV, y XV (Sevilla, 1932). Se reedificaron las iglesias de Santa Marina, San Miguel, San Román y Omnium Sanctorum. 
a la judería de Sevilla ${ }^{31}$, que podría haber incidido en el deterioro de la primera sinagoga. Además, en este momento, se construyeron sinagogas en otras ciudades, como en Toledo donde, entre 1357 y 1363, se levanta la sinagoga de Samuel ha-Leví ${ }^{32}$. De la sinagoga con que guarda más similitudes tipológicas ${ }^{33}$, la de Segovia, no se conoce el origen, aunque también se trata de una obra mudéjar, probablemente del siglo XIV, cuyas referencias decorativas apuntan a la sinagoga de Santa María la Blanca de Toledo ${ }^{34}$. Por último, a partir de $1370^{35}$, comienzan en Sevilla las predicaciones del arcediano de Écija que culminarían con el asalto a la judería de 1391, por lo que no parece probable que la obra se ejecutara en este último periodo (plano 3).

Al transformar la antigua mezquita en sinagoga, se abandonó el antiguo muro de la alquibla (y el mihrab), construyendo un muro paralelo a poca distancia; se reorientó el templo alargándose hacia una nueva cabecera ${ }^{36}$, situándose el hejal, más hacia Jerusalén, en el lado nororiental ${ }^{37}$. La planta se dividió en tres naves longitudinales

${ }^{31}$ Antonio Collantes de TERÁN SÁNCHEZ, «Estudio preliminar», en Relación histórica de la Judería de Sevilla, establecimiento de la Inquisición en ella, su estinción [sic] y colección de los autos de fe, celebrados desde su erección (Sevilla: Sociedad de Bibliófilos Andaluces, 1978), 11.

${ }^{32}$ Referencias a construcciones, reformas y ampliaciones de sinagogas se recogen en RIERA I SANS, Els poders públics i les sinagogues, 190-191.

${ }^{33}$ Existen más referencias a sinagogas basilicales en Francisco CANTERA Burgos, Sinagogas españolas: con especial estudio de la de Córdoba y la toledana de El Tránsito (Madrid: CSIC, 1955). Diego de Espés, secretario del cabildo de Zaragoza, aporta en su Historia Eclesiastica Cesaraugustana interesante descripción complementaria de la sinagoga: «[...] el edificio era como templo de tres navadas, aunque pequeñas, con sus pilares; las Naves de los lados algo bajas, la de en medio más alta; y la techumbre con muchas labores; y con unos morteretes dorados» (ibíd., 363-364).

${ }^{34}$ Esta sinagoga de Toledo se transformó en iglesia también con el nombre de Santa María la Blanca, como la de Sevilla.

35 Antonio Collantes de Terán SÁnchez, «La difícil convivencia entre cristianos, judíos y mudéjares», en De la muerte en Sefarad. La excavación arqueológica en la nueva sede, coord. Isabel SANTANA FALCón (Sevilla: Diputación de Sevilla, 1995), 55-66.

${ }^{36}$ Es sugerente que los dos elementos más significativos de los templos de las dos religiones son incompatibles en la nueva obra; se abandona el muro de la alquibla y se construye uno paralelo a poco distancia, pero de nueva planta, y, por otra parte, se construye un nuevo muro de Jerusalén, sin reutilizar, a su vez, el muro oriental de la mezquita

${ }^{37} \mathrm{Ni}$ la alquibla anterior se dirigía exactamente a La Meca, ni la cabecera de la sinagoga mira exactamente a Jerusalén, entre otros motivos, porque las dos ciudades 


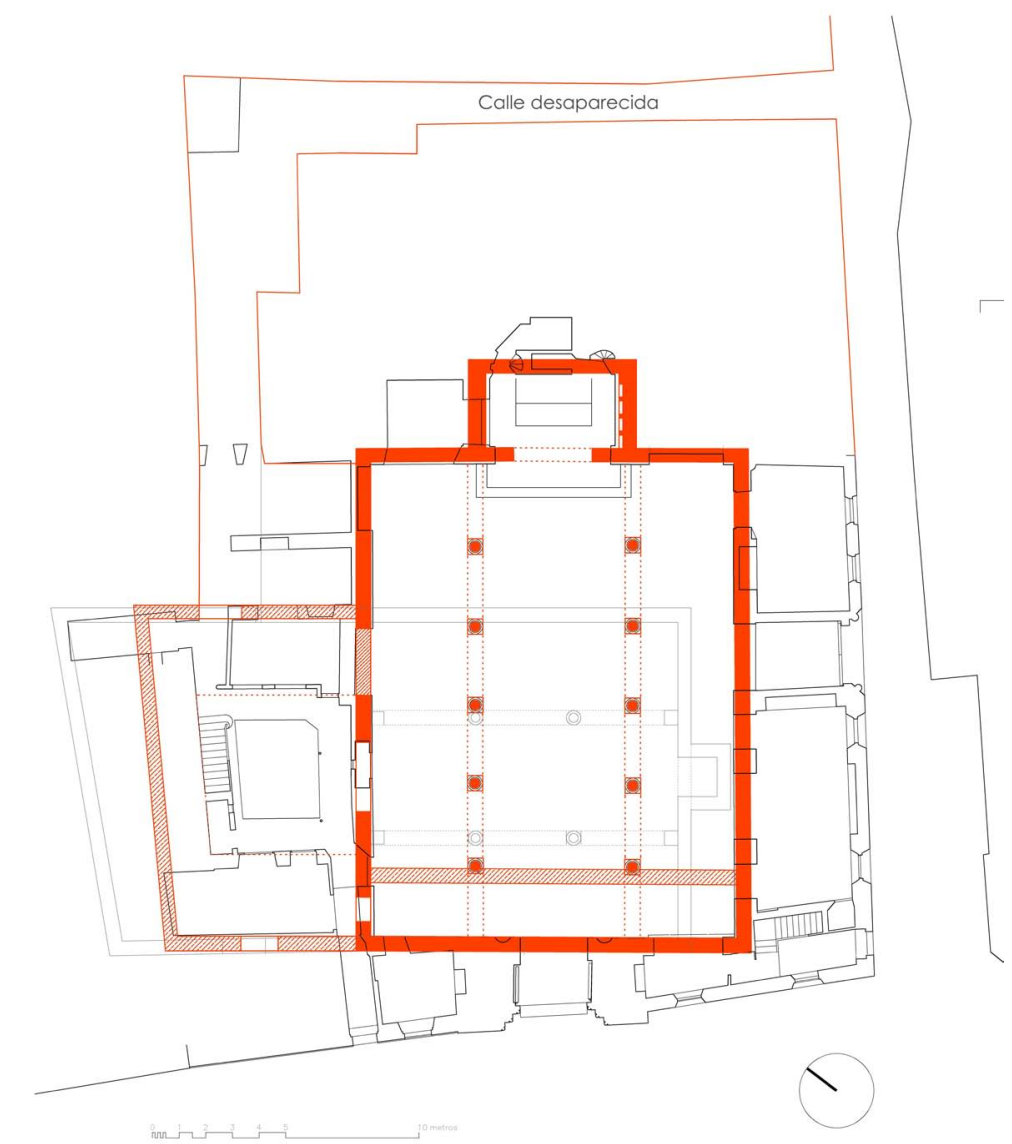

Plano 3. Planta de la sinagoga superpuesta a la planta actual de la iglesia.

en dirección suroeste - noreste. Se reutilizaron los muros norte y oeste de la mezquita previa y, probablemente, se mantuvo la entrada a través del antiguo sahn. Para esta planta se reaprovecharon y, seguramente, se acarrearon más columnas antiguas sobre las que se

tienen rumbos muy similares desde Sevilla. La costumbre de reorientar es más una actitud de cambio, de negación de la religión anterior, que de brújulas y grados. Para cuestiones de la orientación de las mezquitas es clarificador el libro de Monica Rius Piniés, La alquibla en al-Andalus y al-Magrib al-Aqsà [= Anuari de Filologia XXI (1998-99), B-3] (Barcelona: Institut Millàs Vallicrosa de la Ciència Àrab, 2000). Para orientaciones de sinagogas, véase RIERA I SANs, Els poders públics i les sinagogues, 194. 
apoyaron las arquerías de la nave central ${ }^{38}$. En la coronación de los muros de esta nave se construyeron los arquillos ciegos con pequeñas saeteras que han permanecido hasta hoy ocultos sobre las bóvedas

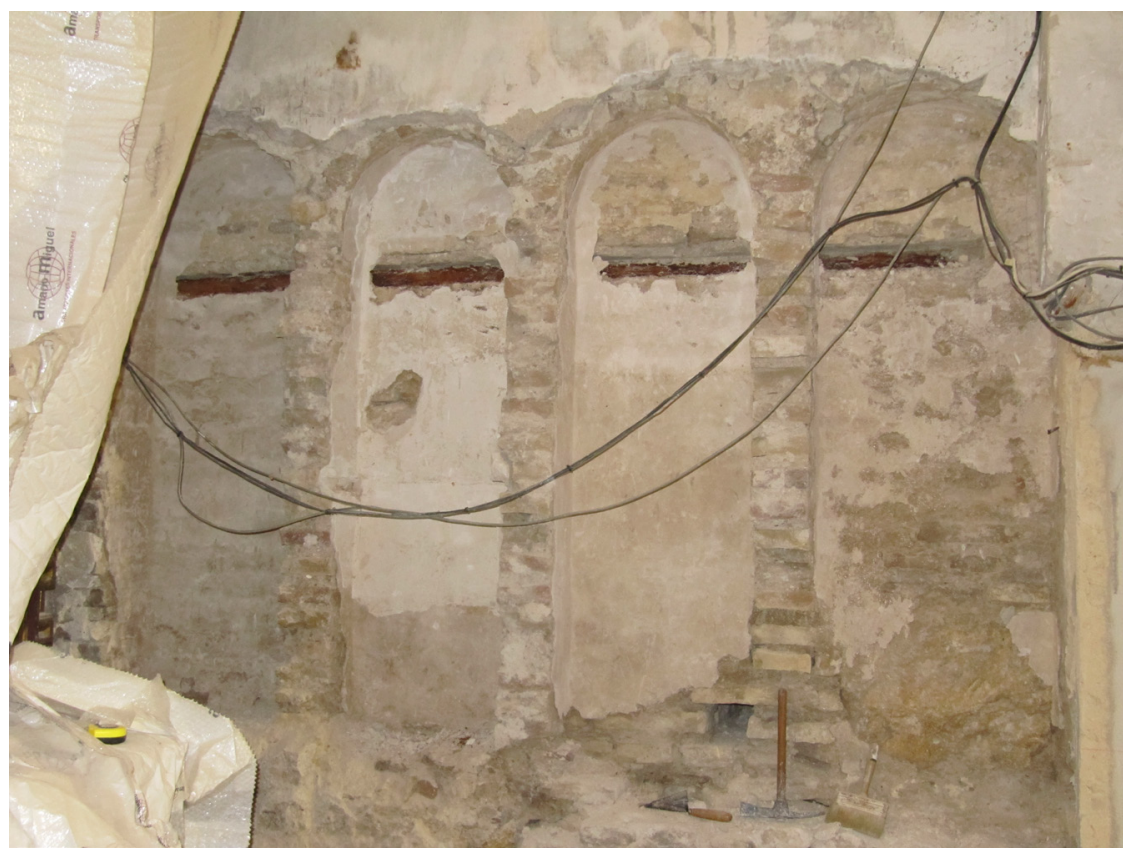

Fotografía 3. Anaqueles en el muro derecho del hejal.

de yeso posteriores. Según los datos aportados por las excavaciones arqueológicas, los muros laterales de la actual capilla mayor de la iglesia corresponderían a la misma obra y serían, por tanto, muros del hejal, este estaba separado de la nave por un arco que tenía menor luz

${ }^{38}$ De estas columnas antiguas son testigos las dos que jalonan la puerta de acceso lateral a la iglesia, desde la calle Archeros, por el centro de la nave derecha. El origen de estas columnas ha llevado a algunos autores a hablar de una antigua basílica visigótica sin ningún otro dato que avale esta hipótesis, más que las acarreables columnas con sus posibles capiteles. Según la descripción de la reforma de la iglesia citada por Fernando de la Torre Farfán, en 1666 (fol. 2): «Tenía el templo antiguo aún más que razonables columnas, tales que sin fealdad pudieran ayudar la obra, por ser iguales, no mal formadas, y de bien foliada piedra. Empero como el primer intento quería que todo fuese nuevo si no se desacreditaron por sí, perdieron por la edad, para acomodarse en tan glorioso oficio». 
que el actual de la iglesia, ya que se han encontrado las trazas de los arranques de los muros de dicho arco. En el muro lateral derecho de este recinto han aparecido, tabicadas, cuatro hornacinas o anaqueles, seguramente relacionados con el depósito de objetos o documentos litúrgicos (fotografía 3). No parece que fuera el arca principal ya que este presidiría el recinto del hejal y estaría situado, probablemente en el eje de la sinagoga (plano 4).

Como la organización de los arquillos que coronan los muros de la nave central coincide con la modulación actual de las columnas de

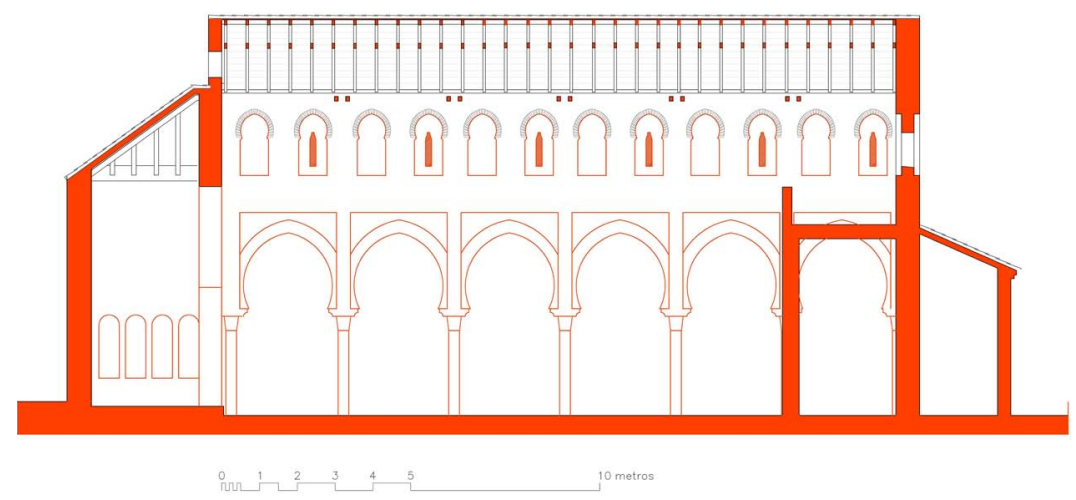

Plano 4. Hipótesis de sección longitudinal de la sinagoga.

la nave, situándose estas en el intereje entre cada dos arquillos, no cabe duda que en el mismo lugar estuvieron las columnas anteriores (fotografía 3) ${ }^{39}$. Estos arcos presentan, de forma alterna, una ventana rasgada verticalmente, a modo de saetera, situada en el eje del hueco y rematadas en un pequeño arco conopial truncado. Ventanas de esta misma forma son la que se sitúan en la parte alta de la sinagoga de Santa María la Blanca de Toledo y que fueron estudiadas por Czekelius ${ }^{40}$. La nave se divide en seis tramos, siendo el primero por los pies levemente más corto que los restantes. Seis tramos por dos muros, a dos arquillos

${ }^{39}$ Las columnas actuales, de mármol rojo, originales de una cantera de Antequera, fueron labradas para la reforma del siglo XVII. Véase AreniLlas, Del Clasicismo al Barroco, 364-365.

${ }^{40}$ Czekelius, «Antiguas sinagogas de España», 335-337. 


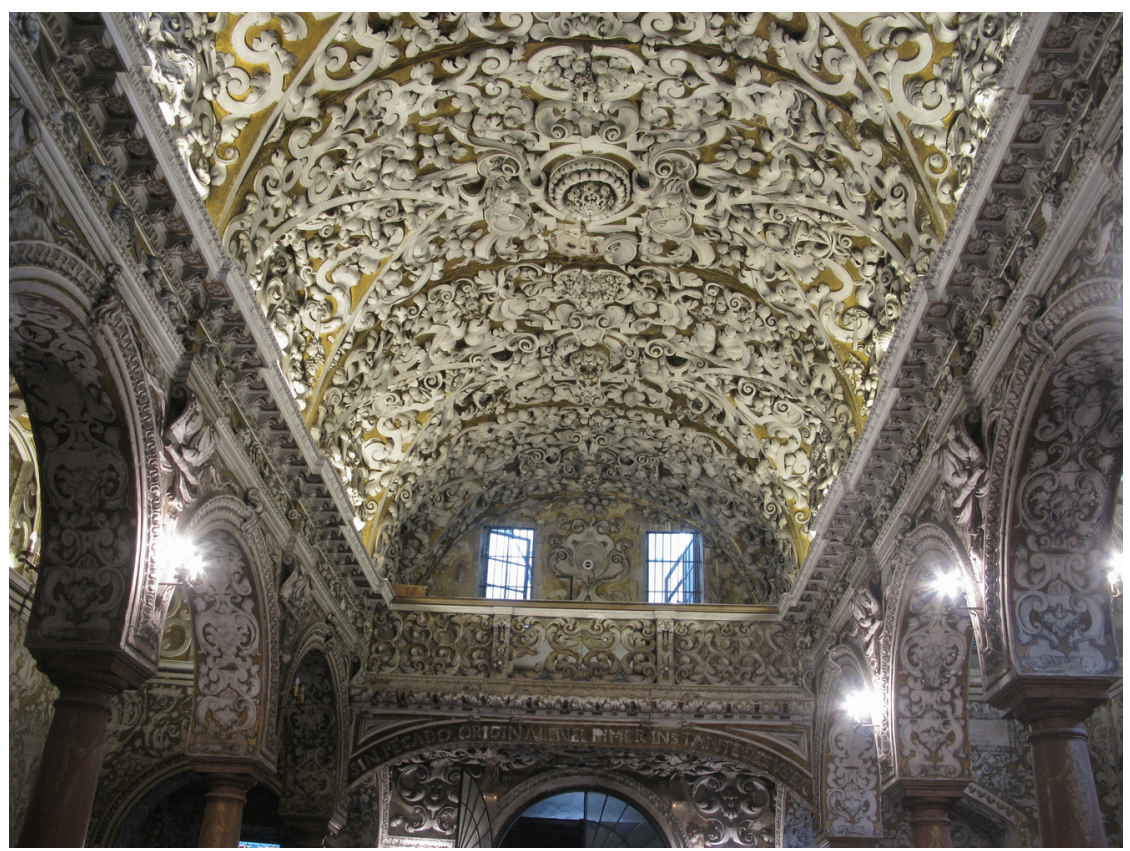

Fotografía 4. Vista del interior de la iglesia con las ventanas en el muro de los pies.

por tramo y una ventana cada dos arcos totalizan doce ventanas; número tan admirado y mencionado en toda la literatura sobre sinagogas ${ }^{41}$. Sin embargo, en el muro de los pies se sitúan otros dos huecos en la misma posición pero con mayor separación. Estos dos huecos se encuentran hoy abiertos con forma rectangular al interior de la nave, probablemente transformados al situarse en el tímpano de la bóveda barroca y comunicados, por tanto, directamente con el interior. Por su posición anómala respecto a la bóveda actual de yeserías, pienso que debería pertenecer a la serie anterior y fueron los únicos reutilizados tras la reconversión cristiana (fotografía 4 y plano 5). Posiblemente, en el muro de cabecera, sobre el arca, pudo haber también alguna ventana

${ }^{41}$ RiERA I SANS, Els poders públics $i$ les sinagogues, según el cual, el Talmud ordena que las sinagogas tengan ventanas, que el Zohar concreta en doce, aunque recuerda que todos los tratadistas están de acuerdo que la recomendación del número de ventanas no se cumplía (ibíd., 188). 


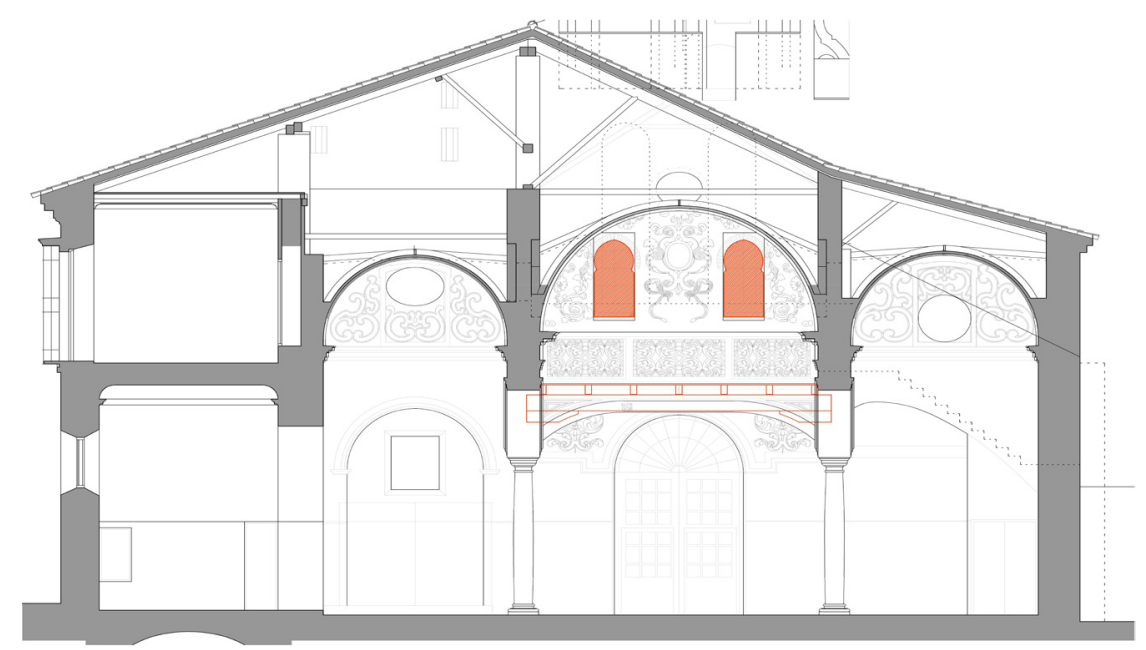

Plano 5. Sección transversal hacia los pies, con las ventanas antiguas restituidas.

más. Las ventanas altas son una constante en las sinagogas ${ }^{42}$ y en la españolas medievales se solían disponer en forma de arquillos, ciegos o no, coronando los muros de las naves principales.

Al existir las pequeñas saeteras pasantes se deduce que estas serían utilizadas para ventilar hacia el exterior ya que la otra posibilidad, la de comunicar la nave central con las naves laterales, no parece probable. La sección de la sinagoga sería, aproximadamente, la expuesta en el dibujo adjunto, de forma que la sección basilical con la nave central peraltada permite la existencia de huecos de iluminación (escasa) y ventilación con los huecos retranqueados de la línea de fachada (plano 6).

Casi alineada con el primer tramo de las naves, ha aparecido una cimentación importante que cruzaba las tres naves y que fue ejecutada en el mismo momento. Sobre ella se apoyaría un muro que debió de configurar el vestíbulo de la sala de oración y espacio auxiliar para el

${ }^{42}$ Jesús Peláez del Rosal, «Las sinagogas medievales españolas en los documentos de la Baja Edad Media (siglos XIII-XV)», (Toledo, 23 de septiembre de 1994), texto accesible en http://www.uco.es/dptos/antiguedadyedadmedia/griego/ publicaciones/docum1016.htm (consulta: 15 marzo 2013). 


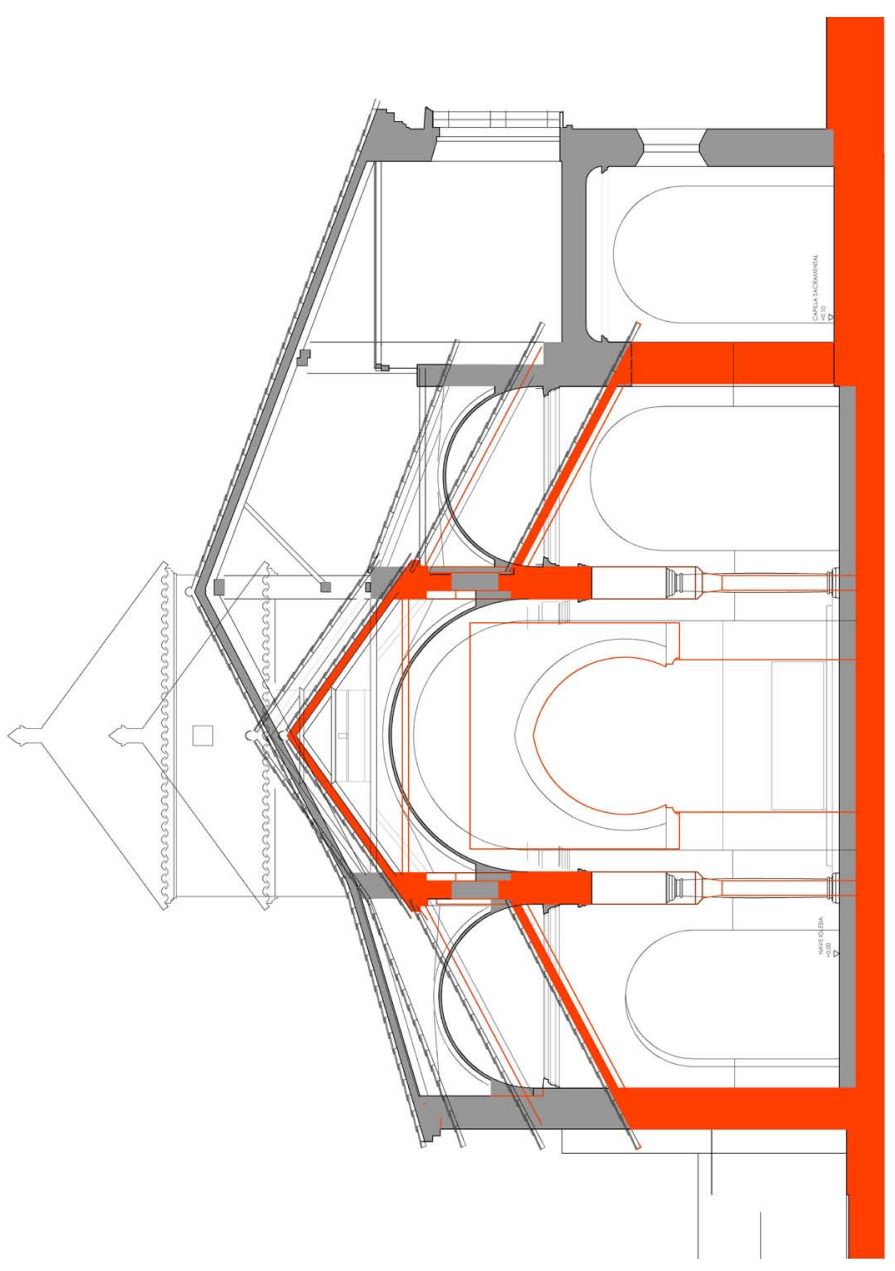

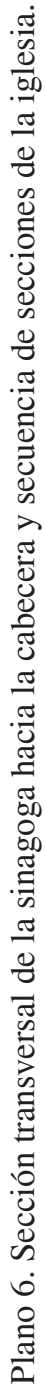


acceso a la tribuna de las mujeres, que podría estar situada sobre él. Por la geometría de la sección no creo probable que la galería de las mujeres se ubicara ni en una entreplanta sobre las naves laterales ni a media altura en las crujías anexas. Como en Santa María la Blanca de Toledo y en Segovia se ignora dónde pudo estar situada, pero no sería extraño que estuviese a los pies de la nave central en una tribuna alta apoyada sobre el muro antes citado, es decir, en la misma forma que se encuentra hoy la tribuna del coro de la iglesia, pero con la parte inferior -actual sotocoro- también separada de la sala. El acceso a este vestíbulo se pudo verificar a través de una pequeña puerta, cuyos restos se descubrieron al retirar los paneles de azulejos en la esquina noroccidental durante las últimas obras y se señalan en el plano adjunto. El muro frontero con la plaza debió permanecer sin aberturas directas y toda la circulación se realizaría a través del antiguo patio.
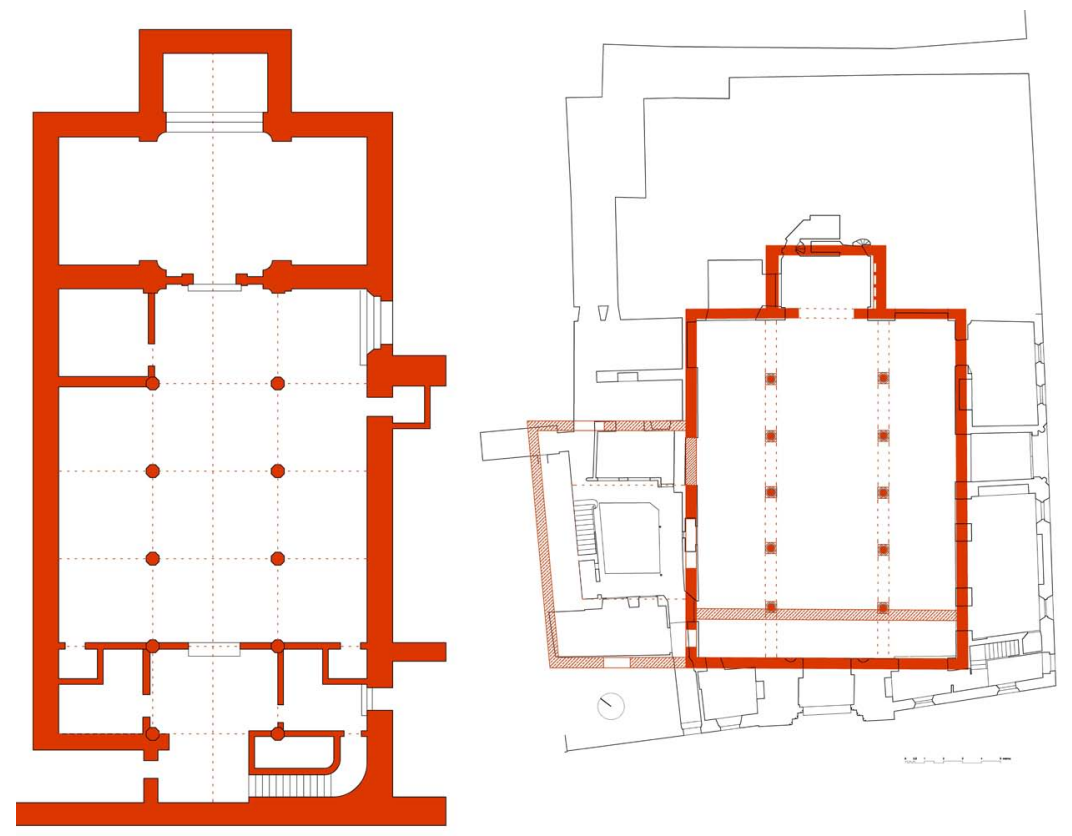

Plano 7. Plantas comparativas de las antiguas sinagogas en las iglesias de Santa María la Blanca y de Segovia. 
La sala de oración tiene unas dimensiones de 13,50 × 17,70 metros sin contar el hejal. Son dimensiones bastantes reducidas si las comparamos con otras mayores, como la de Santa María la Blanca de Toledo o la de Segovia. Comparadas a la misma escala, se destaca la diferencia que presenta con el mismo tipo basilical de la de Segovia (plano 7). La sección longitudinal la supongo bastante parecida en esquema aunque los arcos inferiores en la de Segovia son de herradura redonda y en Sevilla los presumo apuntados, similares a los arquillos de la parte alta, más mudéjares sevillanos.

Dentro de la judería de Sevilla no se tienen más datos sobre la sinagoga que fue sustituida por la iglesia de San Bartolomé. En cambio sí hay noticias sobre la que se pasó a llamar Santa Cruz, pues fue visitada, antes de su demolición, por González de León quien la describe años después ${ }^{43}$. Presentaba asimismo planta basilical de arcos con columnas de granito y eran desiguales en altura y grosor. Aunque esta configuración podría haber sido fruto de transformaciones cristianas, parece probable que fuera su tipología original ${ }^{44}$. Fechado poco antes de su demolición, apareció un proyecto de remodelación del interior del templo en el que se proyectaba sustituir las columnas por pilares ${ }^{45}$. Gracias a este documento podemos tener una idea aproximada de la planta de esta sinagoga; que comparándola, a su vez, con la de Santa María la Blanca sorprende por sus dimensiones, que superan claramente a las de la sinagoga mayor de la judería de Sevilla (plano 8).

${ }^{43}$ Félix GonZÁLEZ de León, Noticia artística de todos los edificios públicos, sagrados y profanos, de esta muy noble ciudad de Sevilla (Sevilla, 1844), 40-42.

${ }^{44}$ Rafael Cómez RAmos, «Arquitectura y simbolismo: una sinagoga sevillana desaparecida», en Imagen y símbolo en la Edad Media andaluza (Sevilla: Universidad de Sevilla, 1990), 123; IDEM, «La antigua sinagoga del barrio de Santa Cruz, en Sevilla», Madrider Mitteilungen 33 (1992), 184-195.

${ }^{45}$ María del Carmen Heredia y Purificación Romero, «La antigua y la actual parroquia de Santa Cruz», Archivo Hispalense 175 (1974), 139-164. Se incluyen copias de los planos de la reforma proyectada. Aunque Santa Cruz podría haber sido ampliada en su etapa cristiana no lo creo que lo fueran los anchos de las naves y presenta unas dimensiones más similares a la de la sinagoga de Segovia. La mezquita del solar de Santa Cruz debió tener acceso por el muro norte. Quizá el ensanche de la calle de las Teresas que hoy se observa todavía sea huella del antiguo patio de la mezquita. La sinagoga conservaría la entrada a través de este patio como era el uso habitual. 

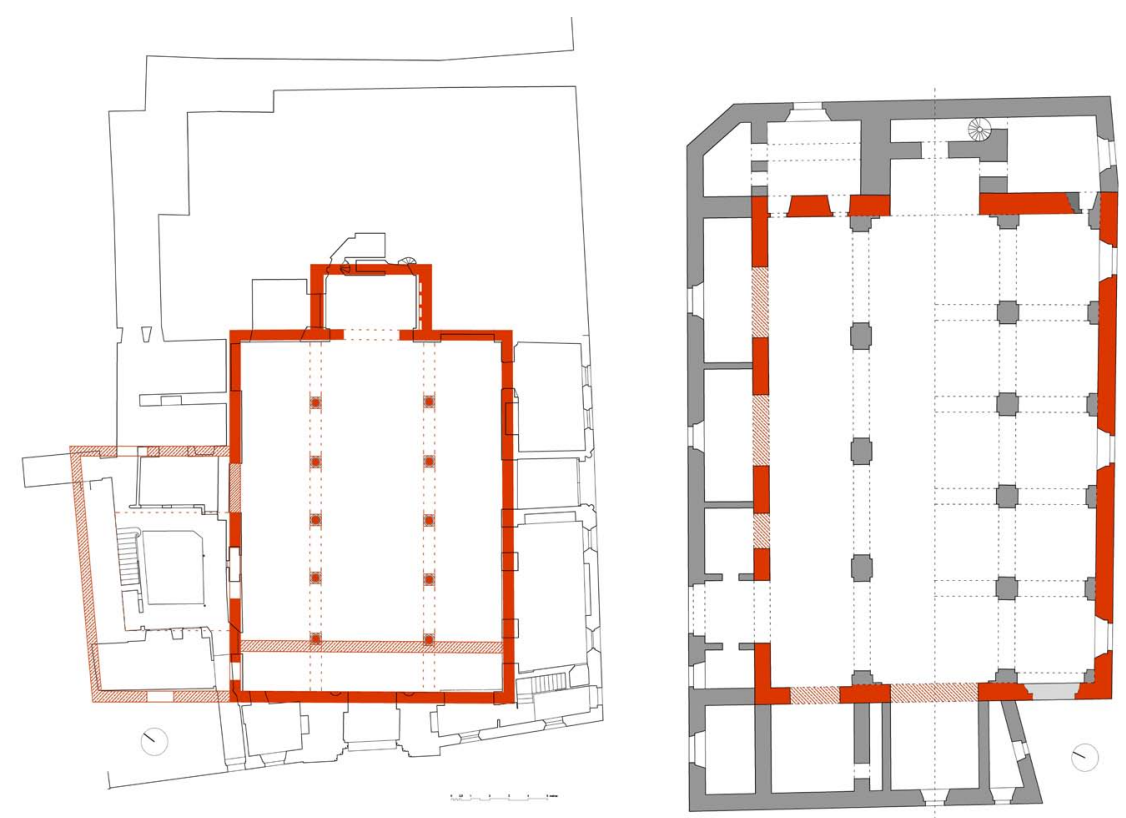

Plano 8. Plantas comparativas de las antiguas sinagogas en las iglesias de Santa María la Blanca y de Santa Cruz.

\section{LA TRANSFORMACIÓN EN IGLESIA}

Las sinagogas principales de Sevilla no fueron destruidas durante el asalto de la judería en 1391, como ocurrió en varias localidades del arzobispado. Para transformar la sinagoga en iglesia no hubo que hacer muchos cambios. Como Jerusalén está al este y ya se había girado una vez la orientación del templo, no fue necesario girarlo más; aparte de que la forma basilical de tres naves alargadas hacia la cabecera era la misma que se utilizaba en las iglesias. Para borrar la presencia del arca se tabicaron los nichos de la Torá y se colocaría el altar cristiano en el fondo. Posiblemente, por necesidades del culto cristiano, se amplió el arco para conseguir más diafanidad entre la nave y el presbiterio. Si hubieran estado decoradas sus paredes con yeserías o pinturas epigráficas hebreas, posiblemente las picarían o se repintaría la iglesia en el caso correspondiente.

Pero la alteración exterior, más visible, se verificó en el acceso y en el símbolo cristiano que representa el campanario. La iglesia eliminó la 
separación entre hombres y mujeres demoliendo el muro del vestíbulo de los pies y abriendo la puerta principal de la iglesia en el centro de dicho muro, en el eje del edificio, directa hasta la calle y casi hacia poniente. Como la antigua sinagoga estaba rodeada completamente por edificaciones propias, en forma de pequeñas tiendas, y por edificios medianeros, el campanario se levantó a modo de torre portada, del que todavía subsiste el primer cuerpo, formado por dos arcos casi enfrentados a los dos arcos de la sinagoga situados en el muro de los pies. En la nueva entrada se construyó una pequeña portada ojival, con escasa arquivolta y enmarcada con la fila de clavos prototípica de las portadas mudéjares sevillanas. El plano de esta portada está en esviaje respecto al plano del muro de los pies de la nave,

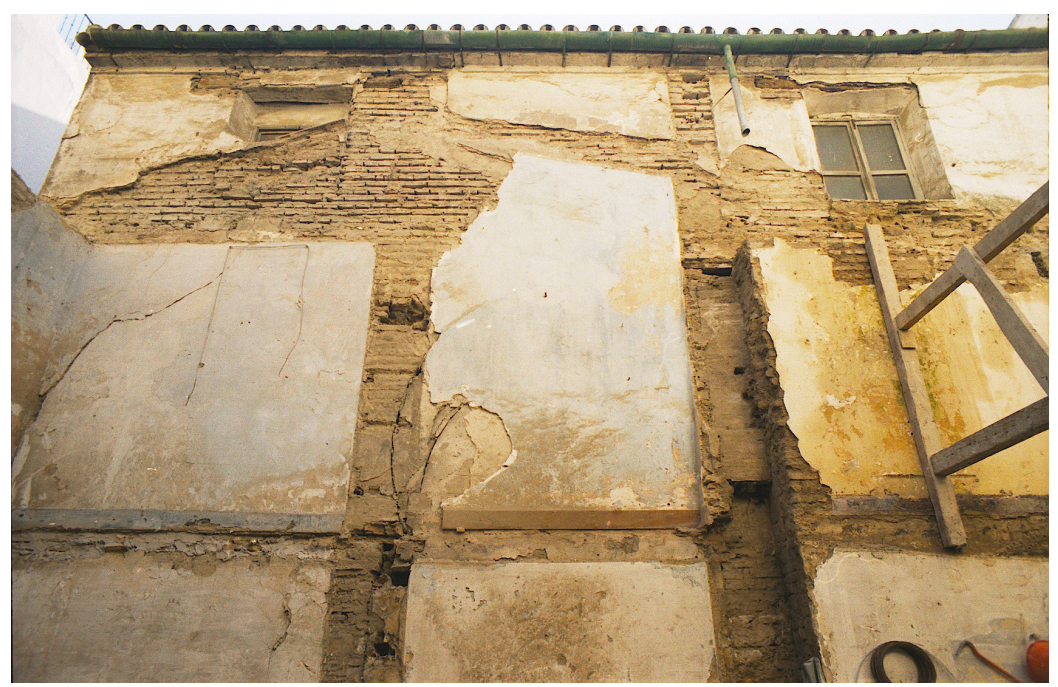

Fotografía 5. Rastro de arco en el muro de la iglesia.

posiblemente debido a nuevas alineaciones urbanas del momento respecto de la antigua mezquita. La nave, con arcos de herradura sobre columnas antiguas reaprovechadas, se mantendría hasta el siglo XVII. Asimismo se mantendría la cubierta de la nave central, con formas de par e hilera sencillas, y las de las naves laterales de pares simples o colgadizo. Aparte del nuevo acceso, la iglesia incorporó capillas en la cabecera de la nave izquierda y más tarde en la de la derecha. Con las dependencias existentes, en el patio se completarían las necesidades eclesiales. 


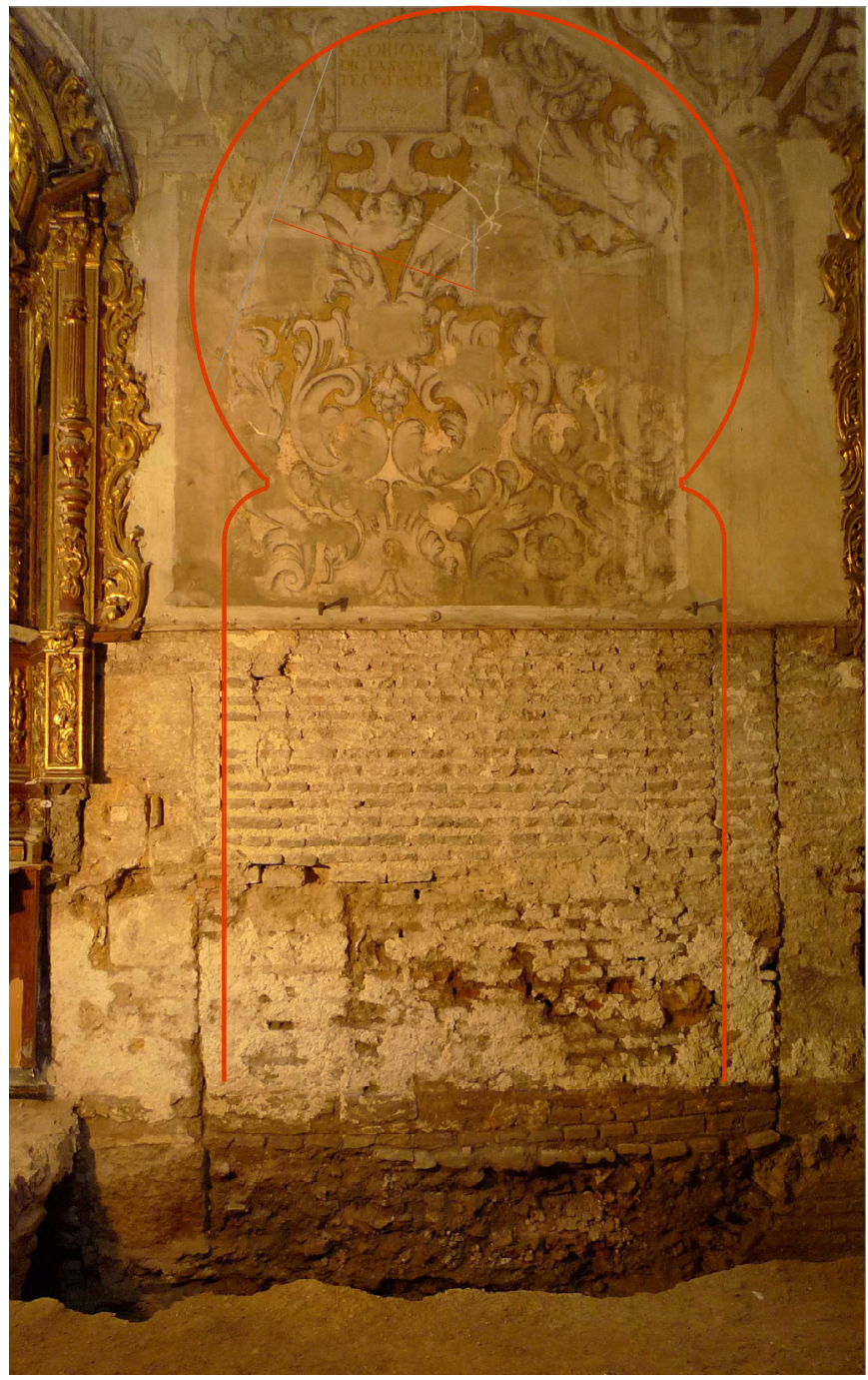

Fotografía 6. Arco por la parte interior del muro.

Sobre dicho patio no hay noticias de la época, pero quizá debió de tener más comunicaciones con la iglesia datables en época cristiana. Aproximadamente en el centro del muro existe un altar que se encuentra empotrado en un nicho rematado en arco de herradura. Junto a este existen los restos de otra puerta o hueco, ya situado fuera el ámbito de la antigua 


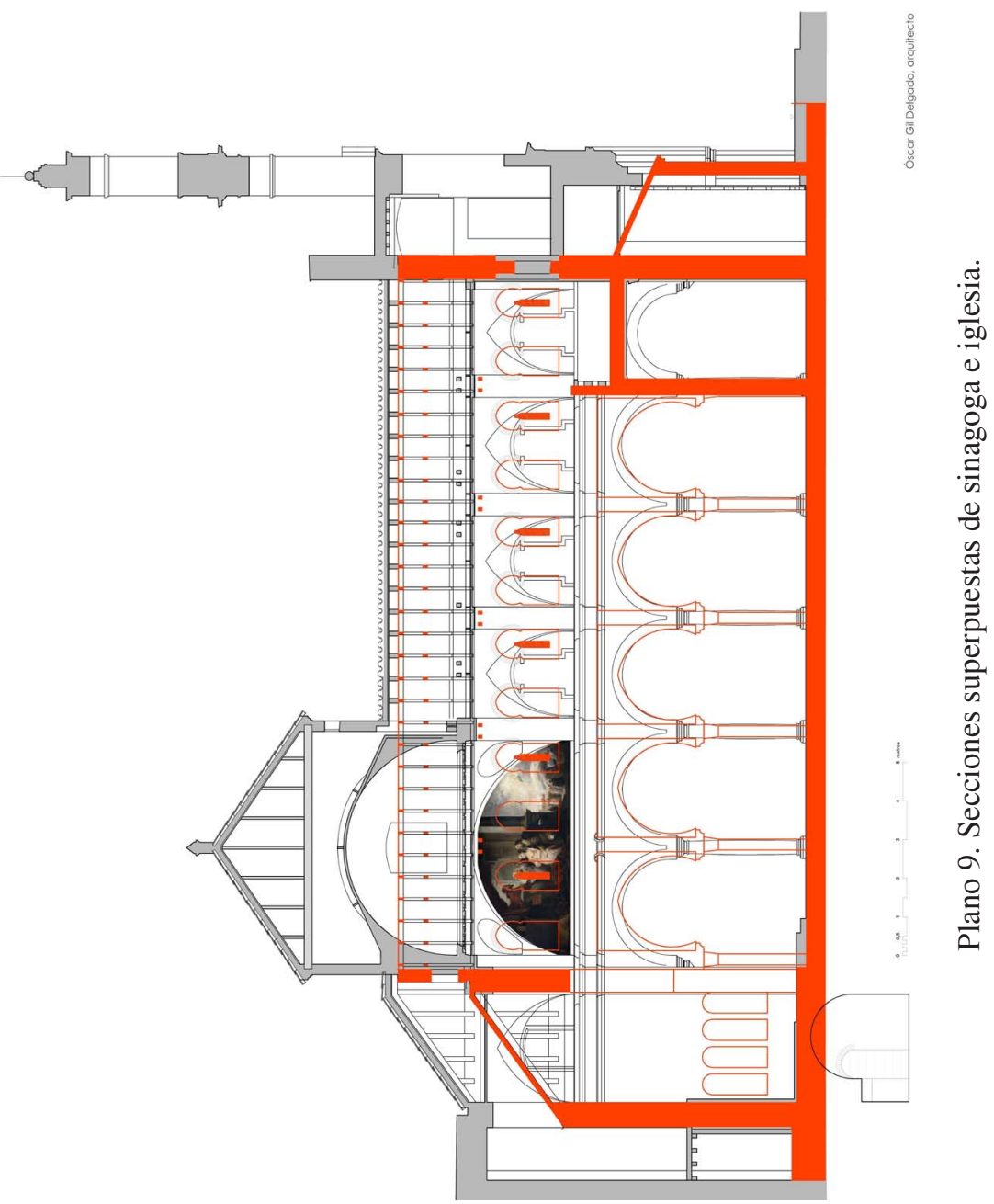


mezquita. Aunque pudieran pertenecer a la etapa judía, parece más probable que fueran huecos abiertos en época cristiana para alojar algún altar, o capilla o paso al antiguo patio o dependencias que lo ocuparon. Como ya se adelantó, este hueco de paso se descubrió, durante la demolición de la casa parroquial, por una fisura que contorneaba el arco (fotografía 5). Esta fisura también debió aparecer, a su vez, por el interior pues, curiosamente, debajo de una colgadura decorativa que ocultaba el muro, apareció dibujada con grafito, en época desconocida, una rectificación de dicho arco y, en parte, sobre un repellado con mortero de dicha fisura. Cuando en las últimas obras se desmontaron los azulejos, aparecieron las mochetas del hueco, cegadas con nuevas fábricas en distinto momento (fotografía 6). El otro hueco con arco sigue acogiendo un altar, el del Descendimiento, y solo se ha podido ver el arranque del arco de herradura tras el retablo. Por el exterior, este arco estaba oculto por el muro que cierra el nicho del retablo. Nada más se puede añadir, de momento, acerca de estos huecos ya que sobre estas modificaciones de la antigua sinagoga no se conocen documentos, hasta pocos años antes de la obra barroca.

\section{CONClusión}

La judería de Sevilla, muy afectada por los sucesos de 1391, conservaba restos ocultos de una de sus sinagogas. Las reparaciones que tanto necesitaba la iglesia de Santa María la Blanca han desvelado antiguas estructuras de la sinagoga y de la mezquita anteriores, apoyadas por diversos trabajos documentales, gráficos y escritos. Estas pervivencias estaban más ocultas por la literatura de un momento fundamental para la ciudad, como fue la mitad del Siglo de Oro, que por el oro que adornaba el interior de la iglesia. La lisonja, exageración y esplendor del barroco solo ensombrecía en un desván, sin ocultarla, la memoria mudéjar del edificio. La mayor aspiración de este artículo es señalar que en este templo sevillano se construye y siguen en pie, juntos, muros de una mezquita, de una sinagoga y de una iglesia (plano 9).

Recibido: $13 / 04 / 2013$

Aceptado: 01/06/2013 